
3

\title{
Use of remotely sensed derived metrics to assess wetland vegetation responses to climate variability induced drought at the Soetendalsvlei wetland system in the Western Cape province of South Africa
}

Noluthando Conelia Ndlala ( $\square$ ndlala.noluthando@gmail.com )

University of the Western Cape Faculty of Natural Science https://orcid.org/0000-0002-7641-6999

Timothy Dube

University of the Western Cape Faculty of Natural Science

\section{Research Article}

Keywords: Drought, evapotranspiration, Heuningnes catchment, NDVI, wetland extent, vegetation health.

Posted Date: June 14th, 2021

DOI: https://doi.org/10.21203/rs.3.rs-247465/v1

License: (c) (1) This work is licensed under a Creative Commons Attribution 4.0 International License.

Read Full License

Version of Record: A version of this preprint was published at African Journal of Aquatic Science on November 11th, 2021. See the published version at https://doi.org/10.2989/16085914.2021.1993778. 


\section{Abstract}

Wetland areas are the most vital ecosystems and they provide important functions towards stabilizing the environment. Hydrological processes in these wetland systems directly affects the productivity of plants. Therefore, assessing vegetation response to climate variability induced drought is vital in wetlands. In this paper, the subtle changes in vegetation distribution were used as a proxy to examine and quantify the extent of drought impacts on wetland ecosystems within the Heuningnes catchment, South Africa. First, vegetation health information was extracted by calculating the normalized difference vegetation index (NDVI) during the wet and dry seasons for the period between 2014 and 2018. The derived NDVI results were further statistical linked to the corresponding rainfall and evapotranspiration (ET) observed during the study period. An analysis of NDVI results revealed that gradual vegetation health change occurred across the study area. The highest derived NDVI (0.5) for wetland vegetation was observed during the year 2014 but progressively declined over the years. Change in vegetation health indicated a significant $(a=0.05)$ and positive correlation to the amount of rainfall received over the same period. The results of this study showed that healthy vegetation deteriorated between the study periods due to the 2015-2017 Western Cape drought.

\section{Introduction}

Wetlands are amongst the Earth's most productive ecosystems. Although they merely occupy 6.2 to $7.6 \%$ of land surface, wetlands are a valuable natural resource of considerable scientific value because they are associated with high biological diversity (Ndirima 2007; Sghair and Goma 2013; Kuria et al. 2014). Wetlands within the Heuningnes catchment are important as natural ecosystem remnants facilitating nutrient cycling, cleaning and the purification process of water, as well as provide scenic attractions for tourists and wildlife habitats (Melendez-Pastor et al. 2010; Chen et al. 2014). Long-term threats to these wetlands include agricultural development, droughts, urban development, climate change and variability as well as other impacts associated with it, such as alien invasion species (Orimoloye et al. 2019; Rebelo et al. 2019). Wetlands are vulnerable and particularly sensitive to fluctuations in the quantity of water supply. In this respect, changes in precipitation due to climate change also pose great challenges to wetland conservation (Erwin 2009).

Inadequate rainfall can induce significant declines in overall plant productivity and even lead to high rates of plant mortality (Touchette et al. 2007; Yu et al.2019). Plants are excellent indicators of wetland condition for many reasons including their relatively high levels of species richness, rapid growth rates, and direct response to environmental change (Cronk and Fennessy 2009; Chatanga and Sieben 2019). Many alterations to the environment that act to degrade wetland ecosystems cause shifts in plant community composition that can be quantified easily (Ehrenfeld 2000). Insufficient water supply may lead to the depletion of soil moisture (Bordi and Sutera 2007), which will further have adverse effects on the growth and health of plants. Increases in temperature also affect wetland systems by accelerating the rate of evaporation and transpiration (Abtew and Melesse 2013). Therefore, the ability to map and assess 
wetland vegetation productivity in detail, especially in response to climate change, will always be an objective in the management of wetland ecosystems.

Monitoring the response of vegetation to drought is important for the sustainable conservation of wetland ecosystems as it is related to the condition of water supply. However, continuous observation and investigation based on physical methods, remains restricted to small geographic coverage, for a specific period of time and it focuses mainly on individual species (Hooper et al. 2005; Guo et al. 2017). In addition, research done physical can be resource intensive and problematic when the study area is remote and hazardous (Daryadel and Talaei 2014). Similarly, developing models for monitoring wetland vegetation at individual levels remains impractical, especially in the light of the global effects of climate change (Xie 2008). Drought indices such as Palmer Drought Severity Index (PDSI) and Standardized Precipitation Index (SPI) become unreliable because their dependence on accuracy of ground observed meteorological inputs that provide sparsely (Zhao et al. 2017) and possess poor spatial resolution at regional scale, especially, in areas` where a few of ground observations are available.

Recent advancements in satellite remote sensing, as powerful means of Earth's surface assessment, have provide efficient, reliable, and affordable monitoring tools for identifying, describing, and mapping the distribution of wetland vegetation with various spatial, temporal, and spectral resolutions at wide scales from local to global (Jones et al. 2009; Kaplan et al. 2019). In particular, the normalized difference vegetation index (NDVI), precipitation and evapotranspiration (ET) products may provide valuable information to understand the wetland ecosystems response to drought because meteorological data obtained from ground observation stations often have poor spatial resolutions (Wan et al. 2004). The NDVI picks up the frequency that the plant leaf releases in order to measure its vigour of the plant's health (Xue and Su 2017; Onyia et al. 2018). Sensors typically capture some combination of visible and nearinfrared light using narrow filters to increase the sensitivity and specificity of the measurements (Lapray et al. 2014). When a plant becomes dehydrated or stressed, the spongy layer of the plant collapses and its leaves reflect less NIR light, yet they still reflect the same amount of light in the visible range (Jacquemoud and Ustin 2019). Thus, vegetation health is one of the most crucial factors to look at when studying the response of wetland ecosystems to a drought.

Investigating the relationship between NDVI and ET or precipitation can infer water stress from different plants. This because sufficient water promotes efficient transpiration and cool plant, while water deficiency promotes closing plant stomata and intense transpiration rate, thus, lower ET represents the stronger evaporative cooling for pixels with the same NDVI (Petropoulos et al. 2009; Yu et al. 2019). As an approach towards assessing wetland vegetation response to climate variability induced drought at the Soetendalsvlei in the Heuningnes Catchment, South Africa, this study mapped and assessed changes in vegetation health and distribution between the years 2014 to 2018, and also examined the relationship between wetland vegetation productivity and rainfall variability.

\section{Materials And Methods}




\section{Description of the study area}

The study focused on the Soetendalsvlei wetland system found in the Heuningnes Catchment, which occurs in the southernmost region of South Africa (Figure 1). The catchment covers an area of about 1 $401 \mathrm{~km}^{2}$ (Hoekstra and Waller 2014) and lies within the Mediterranean climatic zone. The area receives most of its rainfall during the winter season (mid-May to late August). The temperatures in the area vary significantly throughout the year, with an average range of $10^{\circ} \mathrm{C}$ in winter and $28^{\circ} \mathrm{C}$ in summer and a mean annual rainfall of $500 \mathrm{~mm}$ (Hanekom et al. 2009; Herdien et al. 2010). The study site, is a natural fresh water lake which is about $8 \mathrm{~km}$ long and a width of up to $3 \mathrm{~km}$, it occurs along the Nuwejaars River, between Elim and Soetendalsvlei. It is one of the major lakes in the catchment $\left(\sim 20 \mathrm{~km}^{2}\right)$ and South Africa's second largest freshwater lake after Lake Chrissie (Hoekstra \& Waller 2014).

The area is considered a biodiversity hotspot because of the unique animals, flora and landscapes found in the region. It is a home to a highly threatened lowland fynbos type of vegetation and a prominent area for twitches (Gordon et al. 2012). The indigenous fauna and flora of the region form the basis of the fishing and tourism sectors of the economy (Gordon et al. 2011). Marine resources such as linefish, rock lobster, and abalone as well as the bait species contribute a huge amount to the Western Cape economy, with the industry worth over R1.3 billion per year (Turpie et al. 2003). Both the film industry and tourism are dependent on natural resources with an estimated $24 \%$ of foreign visitors to the region being attracted by its scenic beauty. Direct revenue is also generated from the fynbos through harvesting and cultivation of indigenous rooibos tea, wildflowers like proteas, buchu for its aromatic oils, reeds for thatching, and various traditional and commercially marketed medicinal plants (Braschler et al. 2010).

In this study, time series of Landsat images were used to acquire more information about the extent and distribution of vegetation in the site. Landsat 8 (L8) Operational Land Imagery (OLI) Level 1 data acquired for the period of January 2014 to December 2018 were used, freely available from https://earthexplorer.usgs.gov/. The data are available every 16 days with a spatial resolution of $30 \mathrm{~m}$, different bands of the sensor and its specifications are available in Table 1. Cloud-free images and images with less than $10 \%$ cloud cover were selected. Two images representing wet and dry season for each year were obtained and details of these data are provided in Dube and Mutanga (2014). Band 4 (Red) and 5 (NIR) were used for the estimation of NDVI for the wet and dry season of each selected year (Tucker 1979). The L8 images were atmospherically corrected using FLAASH atmospheric correction method. The selection of drought monitoring period was informed by the documented literature and information on the onset of drought (Botai et al. 2017; Leslie and Richman 2018; Otto et al. 2018).

Evapotranspiration (ET), and Precipitation data were acquired from https://wapor.apps.fao.org/catalog/1. The ET data was delivered on a dekad (10-days basis) and is mainly the sum of soil evaporation, canopy transpiration, and evaporation from rainfall intercepted by leaves. The value of each pixel represents the average daily ET in a given dekad (Sazib et al. 2018). Precipitation dataset was obtained from CHIRPS (Climate Hazards Group InfraRed Precipitation with 
Station), a quasi-global rainfall dataset, starting from 1981 up to near present. For CHIRPS, the value of each pixel represents the average of daily precipitation in the dekad expressed in $\mathrm{mm}$ (Funk et al. 2015).

Table 1: Specifications of the satellite images used for spatial assessment of vegetation

\begin{tabular}{|cllll|}
\hline Year & $\begin{array}{l}\text { Date of } \\
\text { Acquisition }\end{array}$ & Image Scene Detail & $\begin{array}{l}\text { Path/ } \\
\text { Row }\end{array}$ & $\begin{array}{l}\text { Land Cloud Cover } \\
(\%)\end{array}$ \\
\hline 2014 & June 21 & LC81740842014172LGN01 & $174 / 84$ & 0.36 \\
\cline { 2 - 5 } & 24 December & LC81740842014348LGN01 & $174 / 84$ & 0.02 \\
\hline 2015 & 8 June & LC81740842015159LGN01 & $174 / 84$ & 0.76 \\
\cline { 2 - 5 } & 17 December & LC81740842015351LGN01 & $174 / 84$ & 0.09 \\
\hline 2016 & 25 May & LC81740842016146LGN01 & $174 / 84$ & 0.3 \\
\cline { 2 - 5 } 2017 & 3 December & LC81740842016338LGN01 & $174 / 84$ & 0.01 \\
\cline { 2 - 6 } & 29 June & LC81740842017180LGN01 & $174 / 84$ & 0.63 \\
\hline 2018 & 18 July & LC81740842017340LGN00 & $174 / 84$ & 3.04 \\
\cline { 2 - 5 } & 25 December & LC8174082018359LGN00 & $174 / 84$ & 0.64 \\
\hline
\end{tabular}

\section{Extraction of Vegetation Cover}

Since there is great variation in vegetation distribution within a given year, in order to obtain abundant cover information about vegetation productivity, wet and dry season vegetation cover in each year were considered for this particular study. In this study, the wet season stretches from May to October and November to April for the dry season. To map and extract the wetland vegetated area and other land cover features that is water and non-vegetated areas within the Soetendalsvlei wetland, the Normalized Difference Vegetation Index: NDVI (Nir - Red/Nir + Red) was calculated. The red and NIR electromagnetic signals (bands) help to differentiate plant from non-plant and healthy plant from stressed plant as well as water from other surface features (Lima et al. 2020). The computed NDVI values ranged from -1 through 0 to 1 , where -ve values approaching -1 correspond to water, values close to zero (-0.1 to 0.1$)$ depicts barren areas e.g. rockoutcrops, sand, bare surfaces and +ve indicate plant health (Bhandari 2012; Wang et al. 2018). Since the derived water and vegetation exhibited unique and distinct NDVI values, we then reclassified the derived NDVI images into three classes (non-vegetated water, and vegetation) using the common geographic information tools as detailed in remote sensing literature (Wang et al. 2018; Wilson and Norman 2018; El-Gammal et al. 2014). 
NDVI thresholds were defined and set for each class and these thresholds were somehow informed by literature (Wilson and Norman 2018; Wang et al. 2018). In the study, thus thresholds were set as following non-vegetated (NDVI range between -0.21 and 0.19 ), vegetated (NDVI $\geq 0.2$ ) and water (NDVI $\leq-02)$. We then conducted accuracy assessment for the derived classes by computing the user, producer and the overall accuracies, validation was done using ground control points, and Google Earth digitized sample points. Further, the derived results were compared to climate data for the areas to determine trends and relationships between derived vegetation metric and climate data. Specifically, correlation analysis was used assess the response of wetland vegetation to drought by evaluating the relationship between NDVI results and rainfall variability. The Pearson product-moment correlation coefficient, better known as the as $r$ was performed to derive the statistical analysis results. The coefficient was calculated for the 12 months data for each year from May to April. The correlation coefficient was computed as:

$$
r=\frac{\sum\left(N D V I_{i}-\overline{N D V I}\right)\left(Y_{i}-\bar{Y}\right)}{\sqrt{\sum\left(N D V I_{i}-\overline{N D V I}\right)^{2}}\left(Y_{i}-\bar{Y}\right)^{2}}
$$

Where $\mathrm{Y}$ is the precipitation or ET and NDVI is the normalized difference vegetation index and average monthly total precipitation or ET for the years 2014, 2015, 2016, 2017 and 2018 adopted in this study. Possible values of $r$ range from -1 to +1 , with values close to 0 signifying little relationship between the two variables. When $r$ is above 0.5 , there is a positive relationship between two variables but there is no significant association. Value ranges from 0.8 to 1 represent a positive significant relationship between the two variables. A detailed description of the methodology is summarized in figure 2 .

\section{Results}

\section{Remotely sensed mapping of wetland vegetation}

The results of the study demonstrated that wetland vegetation was greatly affected by drought between the year 2014 and 2018 (Figure 3 and 4). For instance, the area under vegetation drastically declined in the wetland from 0.13 to $0.07 \mathrm{~km}^{2}$, whereas the area under water declined by $0.85 \mathrm{~km}^{2}$. The year 2016 had the highest wetland vegetation cover during the dry season and the lowest coverage was observed in the year 2018. Further, the wetland vegetation cover varied from 0.13 to $0.07 \mathrm{~km}^{2}$. On the other hand, a similar trend were observed for non-vegetated areas as they increased by about $97 \%$ during the study period. Exceptions were only observed between 2014 and 2016 dry seasons were non-vegetated surface area shrank by nearly half from only $0.46 \mathrm{~km}^{2}$ in 2016 . The highest water surface area in the wetland was observed during the wet season in 2014. However, from 2014 to 2018, the water surface area shrank from 1.34 to $0.49 \mathrm{~km}^{2}$ (63\%). Comparatively, from 2014 to 2018 , the minimum water surface area in the wetland were observed during the 2014 dry season period, which coincided with the onset of drought that took place during the same year. 
Derived classification results showed that wetland vegetation can be mapped with very high accuracies. High classification accuracies in terms of producer, user and overall accuracies were observed (Table 2). For all the remotely sensed derived wetland mapping results, all the accuracy assessment methods were $\pm 80 \%$, demonstrating a commendable classification model performance.

Table 2: Accuracy assessment of Landsat 8 images captured in the years 2014 to 2018 in Soetendalsvlei

\begin{tabular}{llllll}
\hline & Class & PA (\%) & UA (\%) & OA (\%) & Kappa \\
\hline 2014 & Water & 92.4 & 90.7 & 90.5 & 0.89 \\
& Vegetation & 79.3 & 88.5 & & \\
\hline \multirow{2}{2015}{} & Non-vegetated & 100 & 100 & & \\
\hline & Water & 97 & 94.1 & 91.0 & 0.9 \\
\hline & Vegetation & 95.9 & 85.5 & & \\
\hline \multirow{2}{2016}{} & Non-vegetated & 93.5 & 95.6 & & \\
\hline & Water & 93.8 & 93.8 & 88.4 & 0.82 \\
\hline \multirow{2}{*}{2017} & Vegetation & 89.8 & 90.1 & & \\
\hline & Won-vegetated & 81.3 & 100 & & \\
\hline & Vegetation & 79.5 & 90.6 & 87.5 & 0.8 \\
\hline \multirow{2}{2018}{} & Non-vegetated & 83.6 & 97.7 & & \\
\hline & Water & 68.7 & 100 & 89.5 & 0.83 \\
\hline & Vegetation & 77.1 & 100 & & \\
\hline & Non-vegetated & 95.8 & 86.5 & & \\
\hline
\end{tabular}

PA: Producer's Accuracy; UA: User's Accuracy; OA: Overall Accuracy

\section{NDVI seasonal and inter-annual variations of wetland vegetation}

Seasonal and inter-annual comparison of wetland vegetation productivity were assessed, using the NDVI to determine the impact of drought on wetland vegetation condition (Figure 5). The results showed that NDVI varied significant between seasons and between the years. Overall, the highest NDVI was observed in the year 2014, whereas the year 2015 and 2017 exhibited a similar trend. It is however, important to note that during the same years NDVI from wetland vegetation was very low around 0.20 in the wet season. Only the 2017 dry season exhibited a bit of recovery with NDVI increasing to around 0.25 . However, between 2014 and 2018, impact was largely observed during 2018 dry season period were NDVI values were below 0.05 . Inter-annual comparisons demonstrated a sharp decline in wetland vegetation productivity since the onset of drought in 2014 to 2018 with slight recoveries in between the years and seasons.

\section{Relationships between derived NDVI and climate data}

The results indicated that wetland vegetation productivity was largely controlled by rainfall availability and evapotranspiration rates. The results from table 3 showed high correlations between wetland 
vegetation derived NDVI and rainfall as well as evapotranspiration. For example, for all the years NDVI and rainfall correlations coefficients were high and positive, on average above 0.80 whereas for NDVI and evapotranspiration the relationships were significantly but above -0.50 . Figure 6 further details the observed monthly NDVI, precipitation and evapotranspiration trends for the entire study period. It can be observed that evapotranspiration and precipitation controlled or had a bearing on NDVI or wetland vegetation productivity.

Table 3: NDVI vs. Climate data statistical relationships

\begin{tabular}{|l|l|l|}
\hline Year & NDVI vs. Precipitation & NDVI vs. ET \\
\hline 2014 & $0.8^{*}$ & -0.70 \\
\hline 2015 & $0.9^{*}$ & -0.50 \\
\hline 2016 & $0.92^{*}$ & -0.70 \\
\hline 2017 & $0.8^{*}$ & -0.60 \\
\hline 2018 & $0.8^{*}$ & Insignificant association at $r=0.06$ \\
\hline
\end{tabular}

\section{* represents significant positive relationships}

\section{Discussion}

\section{Wetland vegetation growth dynamics between the years 2014, 2015, 2016, 2017 and 2018}

Wetlands comprise of notable attributes of species diversity, richness, abundance and succession, and they are therefore considered to be the most dominant and important ecosystems, globally (Mitsch et al. 2015). This study examined changes in wetland cover to determine the ecosystem's response to drought by using remote sensing techniques. Work done in this study has relevance to the maintenance of ecological processes and quantification of natural disasters impacts because it explores: 1) spatial, temporal and seasonal variations of wetland cover; 2) seasonal variability of wetland vegetation health; 3 ) the link between wetland vegetation growth dynamics and rainfall variability to assess the response of wetland ecosystems to drought.

An analysis of classified maps revealed that gradual ecosystem change occurred across the study area. Other studies such as that by Middleton and Kleinebecker (2012) done to assess the effects of climate change induced drought on freshwater wetlands, and that of Belle et al. (2018) in the eastern Free State, South Africa, confirm that vital wetland productivity processes that sustain biodiversity in the ecosystem may be critically affected by the occurrence of a drought. Climate change induced drought, especially in arid regions, drives change in hydrology and vegetation health, thus affecting ecological processes within the wetland ecosystem. 
This study suggests that the decline in vegetation extent and water, and increase non-vegetated area in the wetland was a result of rainfall variability. Furthermore, climate change is predicted to increase drought, the number of high heat days, and the frequency of severe storms, all of which affected wetland ecosystems. Results for wetland transition shown in this study are comparable to Ridolfi et al. (2006), who observed that wetland ecosystems are vulnerable to disturbances such as a severe drought and may respond to biomass losses with highly irreversible catastrophic shifts to unvegetated conditions. Similarly, Nhamo et al. (2017), using the Landsat satellite data to delineate wetland extent and assess seasonal variations in South Africa during the period of 2000 to 2015, found a continues decline in wetland area and the minimum value was observed in 2015 which coincided with an El Nino associated drought in the study area (Rembold et al. 2016; FAO 2016).

\section{Impact of meteorological data trends on wetland vegetation productivity}

Based on long-term ( 5 years) data, this study examined the influence of rainfall variability on the productivity of wetland vegetation in the Soetendalsvlei wetland system. The relationship between wetland vegetation health and quantity as well as the temporal patterns of rainfall variability were assessed and yielded two key results. Firstly, over the past 5 years, NDVI (Vegetation health) significantly and positively correlated with precipitation; and secondly, the NDVI and ET showed an opposite trend, ET exceeds the amount of precipitation during the period of this study.

The results of this study highlight the importance of rainfall variability on wetland vegetation productivity. One explanation is that rain events provide sufficient soil moisture and maintain high water availability (Merolla 2012). In arid and semiarid ecosystems, water is typically a limiting factor for plant health, and available moisture generally increases plant biomass (Twisa and Buchroithner 2019). Photosynthesis of plants depends on water availability, therefore, insufficient water availability can minimize the assimilation of carbon, thereby decreasing wetland vegetation productivity (Pinheiro and Chaves 2011).

For instance, the results of the study by Barros and Albernaza (2014) found that an elevation in water availability leads to a reduction in wetland vegetation growth rates or the reproductive success of many species. Wetland vegetation have highly developed root systems that holds the soil in place and filter pollutants, naturally improving water quality (Finlayson et al. 2015). Therefore, a drought will likely cause the loss of, or reduction in wetlands and will challenge the adaptability, composition and distribution of wetland plants. Moreover, if wetland vegetation productivity is challenged, pollutants could become more concentrated in wetlands and this will affect water quality.

\section{Remote sensing spatial and seasonal variations of wetland vegetation}

Similar to other arid lands, vegetation, precipitation and ET in the study area is both spatial and temporally heterogeneous, making ground-based measurements invaluable. However, the study area is remote and the use of in-situ methods can be resource intensive and problematic when the study area is remote and hazardous (Adam et al. 2010). Remote sensing therefore provides invaluable means of monitoring vegetation to assess environmental conditions in wetland ecosystems (Amler et al. 2015). 
The tool has been popular for collecting meteorological data, and offers spatially explicit data, as well as repeated observations and covers large geographic locations (Boisvenue and White. 2019).

Remote sensing images are key data sources for earth monitoring programs considering the great advantages that they have (Makapela et al. 2015). For instance, it is more easily obtainable to produce and update vegetation inventories over large regions if aided by satellite imagery and appropriate imagery analysis. A growing number of studies have examined the response of wetland vegetation productivity to drought by using remote sensed data (Santos et al. 2019; Easterday et al. 2019; Adamu et al. 2018; Wilson and Norman 2018; Nhamo et al. 2017). However, although remote sensing technology has tremendous advantages over traditional methods in vegetation mapping, we should have a clear understanding of its limitations. It is important to understand how well will the chosen vegetation index/ drought proxy represents actual vegetation community composition. Also it is critical to determine how effectively images from remote sensing capture the distinguishing features of each mapping unit within the classification and how well these mapping units are delineated by photo interpreters. In fact a well-fit vegetation classification system should be carefully designed according to the objective of the study in order to better represent actual vegetation community compositions.

The capacity to accurately detect wetlands in moderate resolution data from Landsat is desired to facilitate understanding of spatial and temporal dynamics of wetlands. Landsat provides the highest spatial resolution and longest systematically sampled historical remote sensing record dating back to approximately 1984 (Pouliot et al. 2019). Thus, Landsat offers the greatest opportunity for understanding wetland change and drivers of these changes. There are only a few wetland studies reporting accuracy for small extent applications for similar ecosystems and sensors. At the reduced three-class thematic level Hird et al. (2017) reported an overall accuracy of $85 \%$ within the Central Canadian Boreal Forest Region, whereas Filatow and Carswel (2018) achieved a satisfactory accuracy of $91 \%$ in northern British Columbia.

Vegetation index NDVI was used to detect any significant differences in vegetation cover between the years 2014 to 2018 . The results indicated that NDVI was able to discriminate wetland vegetation from other classes within the study area. Results required for drought impacts assessment showed the change in landcover distribution and vegetation productivity between 2014, 2015, 2016, 2017 and 2018. These results clearly revealed that the wetland was negatively affected by the long-term drought. Temporal remotely sensed data enabled the assessment of wetland vegetation health condition as far as back as 2014, therefore remote sensing provided an effective tool in analysing and determining vegetation changes in wetlands under different management regimes. Frequent wetland monitoring is important for timely intervention in the case of an identified negative change. Remote sensing has shown its strength in wetland mapping and for monitoring wetland dynamics over time and is thus an important tool for wetland management.

\section{Conclusion}


Temporal and spatial distribution of wetland cover classes and vegetation cover was assessed using NDVI to examine the impact of rainfall variability (drought) on wetland vegetation. Results showed that a significant variation in the wetland surface area from 2014 to 2018. Specifically vegetation and water decreased significantly over the monitoring period, while the extent of bare surface increased rapidly. Wetland extent mapping was achieved with an average overall accuracies (85-90\%) in this study. Further, Vegetation productivity significantly and positively correlated with precipitation over the past five years, while ET showed a negative significant relationship, ET exceeds the amount of precipitation during the period of this study. From the observation of the whole study period, healthy vegetation has deteriorated due to drought that occurred in the study area between the monitoring periods. The amount of rainfall entering into an ecosystem is typically a limiting factor for plant health, the results of this study highlight the importance of rainfall variability on wetland vegetation productivity.

\section{Declarations}

\section{Competing Interests}

There are no relevant financial or non-financial competing interests to report.

\section{Funding Info}

We thank the South African National Space Agency (SANSA) for funding this work.

\section{Author contribution}

Ndlala NC conceived of the presented idea, developed the theory and performed the computations. Prof Dube T verified the analytical methods and supervised the findings of this work.

\section{Data Availability}

Data were derived from the following resources available in the public domain: https://earthexplorer.usgs.gov/ and https://wapor.apps.fao.org/catalog/1

\section{References}

Abtew, W. and Melesse, A., 2013. Wetland evapotranspiration. In Evaporation and Evapotranspiration (pp. 93-108). Springer, Dordrecht.

Adam, E., Mutanga, O. and Rugege, D., 2010. Multispectral and hyperspectral remote sensing for identification and mapping of wetland vegetation: a review. Wetlands Ecology and Management, 18(3), pp.281-296.

Adamu, B., Tansey, K. and Ogutu, B., 2018. Remote sensing for detection and monitoring of vegetation affected by oil spills. International Journal of Remote Sensing, 39(11), pp.3628-3645. 
Amler, E., Schmidt, M. and Menz, G., 2015. Definitions and mapping of east African wetlands: A review. Remote Sensing, 7(5), pp.5256-5282.

Barros, D.F. and Albernaz, A.L.M., 2014. Possible impacts of climate change on wetlands and its biota in the Brazilian Amazon. Brazilian Journal of Biology, 74(4), pp.810-820.

Belle, J.A., Collins, N. and Jordaan, A., 2018. Managing wetlands for disaster risk reduction: A case study of the eastern Free State, South Africa. Jàmbá: Journal of Disaster Risk Studies, 10(1), pp.1-10.

Boisvenue, C. and White, J.C., 2019. Information needs of next-generation forest carbon models: opportunities for remote sensing science. Remote Sensing, 11(4), p.463.

Bordi, I. and Sutera, A., 2007. Drought monitoring and forecasting at large scale. In Methods and tools for drought analysis and management (pp. 3-27). Springer, Dordrecht.

Botai, C.M., Botai, J.O., De Wit, J.P., Ncongwane, K.P. and Adeola, A.M., Drought characteristics over the Western Cape Province, South Africa. Water. 2017; 9: 876-892.

Braschler, B., Du Plessis, D. and Jumbam, K.R., 2010. Raising awareness of South Africa's biodiversity. Quest, 6(2), pp.8-10.

Chatanga, P. and Sieben, E.J., 2019. Ecology of palustrine wetlands in Lesotho: Vegetation classification, description and environmental factors. Koedoe, 61(1), pp.1-16.

Chen, Y., He, X., Wang, J. and Xiao, R., 2014. The influence of polarimetric parameters and an object-based approach on land cover classification in coastal wetlands. Remote Sensing, 6(12), pp.12575-12592.

Cronk, J.K. and Fennessy, M.S., 2009. Wetland Plants. Reference Module in Earth Systems and Environmental Sciences. Encyclopedia of Inland Waters, pp.590-598.

Daryadel, E. and Talaei, F., 2014. Analytical study on threats to wetland ecosystems and their solutions in the Framework of the Ramsar Convention. World Acad Sci Eng Technol, pp.2091-2101.

Dube, T. and Mutanga, O., 2015. Evaluating the utility of the medium-spatial resolution Landsat 8 multispectral sensor in quantifying aboveground biomass in uMgeni catchment, South Africa. ISPRS Journal of Photogrammetry and Remote Sensing, 101, pp.36-46.

Easterday, K., Kislik, C., Dawson, T.E., Hogan, S. and Kelly, M., 2019. Remotely sensed water limitation in vegetation: insights from an experiment with unmanned aerial vehicles (UAVs). Remote Sensing, 11(16), p.1853.

Ehrenfeld, J.G., 2000. Evaluating wetlands within an urban context. Urban Ecosystems, 4(1), pp.69-85.

Erwin, K.L., 2009. Wetlands and global climate change: the role of wetland restoration in a changing world. Wetlands Ecology and management, 17(1), p.71. 
FAO (Food and Agriculture Organisation of the United Nations) (2016) El Niño: Preparedness and Response: Situation Report-March 2016. Food and Agriculture Organisation of the United Nations, Rome.

Finlayson, C.M., Horwitz, P. and Weinstein, P. eds., 2015. Wetlands and human health (Vol. 5). Springer.

Funk, C., Peterson, P., Landsfeld, M., Pedreros, D., Verdin, J., Shukla, S., Husak, G., Rowland, J., Harrison, L., Hoell, A. and Michaelsen, J., 2015. The climate hazards infrared precipitation with stations-a new environmental record for monitoring extremes. Scientific data, 2(1), pp.1-21

Gordon, N., Adams, J.B. and Garcia-Rodriguez, F., 2011. Water quality status and phytoplankton composition in Soetendalvlei, Voëlvlei and Waskraalsvlei, three shallow wetlands on the Agulhas Plain, South Africa. African Journal of Aquatic Science, 36(1), pp.19-33.

Gordon, N., García-Rodríguez, F. and Adams, J.B., 2012. Paleolimnology of a coastal lake on the Southern Cape coast of South Africa: Sediment geochemistry and diatom distribution. Journal of African Earth Sciences, 75, pp.14-24.

Guo, M., Li, J., Sheng, C., Xu, J. and Wu, L., 2017. A review of wetland remote sensing. Sensors, 17(4), p.777.

Hird, J.N., DeLancey, E.R., McDermid, G.J. and Kariyeva, J., 2017. Google Earth Engine, open-access satellite data, and machine learning in support of large-area probabilistic wetland mapping. Remote sensing, 9(12), p.1315.

Hooper, D.U., Chapin lii, F.S., Ewel, J.J., Hector, A., Inchausti, P., Lavorel, S., Lawton, J.H., Lodge, D.M., Loreau, M., Naeem, S. and Schmid, B., 2005. Effects of biodiversity on ecosystem functioning: a consensus of current knowledge. Ecological monographs, 75(1), pp.3-35.

Jacquemoud, S., and Ustin, S., 2019. Variation Due to Leaf Structural, Chemical, and Physiological Traits. In: Leaf Optical Properties. Cambridge: Cambridge University Press, pp.170-194.

Jones, K., Lanthier, Y., van der Voet, P., van Valkengoed, E., Taylor, D. and Fernández-Prieto, D., 2009. Monitoring and assessment of wetlands using Earth Observation: The GlobWetland project. Journal of environmental management, 90(7), pp.2154-2169.

Kaplan, G., Avdan, Z.Y. and Avdan, U., 2019. Mapping and monitoring wetland dynamics using thermal, optical, and SAR remote sensing data. Wetlands Management: Assessing Risk and Sustainable Solutions, 87.

Kuria, D.N., Menz, G., Misana, S., Mwita, E., Thamm, H.P., Alvarez, M., Mogha, N., Becker, M. and Oyieke, H., 2014. Seasonal vegetation changes in the Malinda Wetland using bi-temporal, multi-sensor, very high resolution remote sensing data sets. Advances in Remote Sensing, 3(01), p.33. 
Lapray, P.J., Wang, X., Thomas, J.B. and Gouton, P., 2014. Multispectral filter arrays: Recent advances and practical implementation. Sensors, 14(11), pp.21626-21659.

Makapela, L., Newby, T., Gibson, L.A., Majozi, N., Mathieu, R., Ramoelo, A., Mengistu, M.G., Jewitt, G.P.W., Bulcock, H.H., Chetty, K.T. and Clark, D., 2015. Review of the use of Earth Observations Remote Sensing in Water Resource Management in South Africa. Water Research Commission, Pretoria, Report KV329/15.

Melendez-Pastor, I., Navarro-Pedreno, J., Gómez, I. and Koch, M., 2010. Detecting drought induced environmental changes in a Mediterranean wetland by remote sensing. Applied Geography, 30(2), pp.254262.

Merolla, S., 2012. The effect of floods and high rainfall on the water quality in selected sub-areas of the upper Vaal Catchment (Doctoral dissertation, University of Johannesburg).

Middleton, B.A. and Kleinebecker, T., 2012. The effects of climate-change-induced drought and freshwater wetlands. In Global Change and the Function and Distribution of Wetlands (pp. 117-147). Springer, Dordrecht.

Mitsch, W.J., Bernal, B. and Hernandez, M.E., 2015. Ecosystem services of wetlands.

Ndirima, Z., 2007, March. Mapping and monitoring wetland vegetation used by wattled cranes using remote sensing: case of Kafue flats, Zambia. ITC.

Nhamo, L., Magidi, J. and Dickens, C., 2017. Determining wetland spatial extent and seasonal variations of the inundated area using multispectral remote sensing. Water $S A, 43(4)$, pp.543-552.

Onyia, N.N., Balzter, H. and Berrio, J.C., 2018. Normalized difference vegetation vigour index: A new remote sensing approach to biodiversity monitoring in oil polluted regions. Remote Sensing, 10(6), p.897.

Orimoloye, I.R., Ololade, O.O., Mazinyo, S.P., Kalumba, A.M., Ekundayo, O.Y., Busayo, E.T., Akinsanola, A.A. and Nel, W., 2019. Spatial assessment of drought severity in Cape Town area, South Africa. Heliyon, 5(7), p.e02148.

Otto, F.E., Wolski, P., Lehner, F., Tebaldi, C., Van Oldenborgh, G.J., Hogesteeger, S., Singh, R., Holden, P., Fučkar, N.S., Odoulami, R.C. and New, M., 2018. Anthropogenic influence on the drivers of the Western Cape drought 2015-2017. Environmental Research Letters, 13(12), p.124010.

Petropoulos, G., Carlson, T.N., Wooster, M.J. and Islam, S., 2009. A review of Ts/VI remote sensing based methods for the retrieval of land surface energy fluxes and soil surface moisture. Progress in Physical Geography, 33(2), pp.224-250.

Pinheiro, C. and Chaves, M.M., 2011. Photosynthesis and drought: can we make metabolic connections from available data. Journal of experimental botany, 62(3), pp.869-882. 
Rebelo, A.J., Morris, C., Meire, P. and Esler, K.J., 2019. Ecosystem services provided by South African palmiet wetlands: A case for investment in strategic water source areas. Ecological Indicators, 101, pp.7180.

Rembold, F., Kerdiles, H., Lemoine, G. and Perez-Hoyos, A., 2016. Impact of El Niño on agriculture in Southern Africa for the 2015/2016 main season. Joint Research Centre (JRC) MARS Bulletin-Global Outlook Series. European Commission, Brussels.

Richman, M.B. and Leslie, L.M., 2018. The 2015-2017 Cape Town Drought: Attribution and Prediction Using Machine Learning. Procedia Computer Science, 140, pp.248-257.

Ridolfi, L., D'Odorico, P. and Laio, F., 2006. Effect of vegetation-water table feedbacks on the stability and resilience of plant ecosystems. Water Resources Research, 42(1).

Santos, C.A.G., Neto, R.M.B., da Silva, R.M. and dos Santos, D.C., 2019. Innovative approach for geospatial drought severity classification: a case study of Paraíba state, Brazil. Stochastic Environmental Research and Risk Assessment, 33(2), pp.545-562.

Sazib, N., Mladenova, I. and Bolten, J., 2018. Leveraging the google earth engine for drought assessment using global soil moisture data. Remote sensing, 10(8), p.1265.

Sghair, A. and Goma, F., 2013. Remote sensing and GIS for wetland vegetation study (Doctoral dissertation, University of Glasgow).

Touchette, B.W., lannacone, L.R., Turner, G.E. and Frank, A.R., 2007. Drought tolerance versus drought avoidance: a comparison of plant-water relations in herbaceous wetland plants subjected to water withdrawal and repletion. Wetlands, 27(3), pp.656-667.

Tucker, C.J., 1979. Red and photographic infrared linear combinations for monitoring vegetation. Remote sensing of Environment, 8(2), pp.127-150.

Turpie, J.K., Heydenrych, B.J. and Lamberth, S.J., 2003. Economic value of terrestrial and marine biodiversity in the Cape Floristic Region: implications for defining effective and socially optimal conservation strategies. Biological conservation, 112(1-2), pp.233-251.

Twisa, S. and Buchroithner, M.F., 2019. Seasonal and Annual Rainfall Variability and Their Impact on Rural Water Supply Services in the Wami River Basin, Tanzania. Water, 11(10), p.2055.

Wan, Z., Wang, P. and Li, X., 2004. Using MODIS land surface temperature and normalized difference vegetation index products for monitoring drought in the southern Great Plains, USA. International journal of remote sensing, 25(1), pp.61-72.

Wilson, N.R. and Norman, L.M., 2018. Analysis of vegetation recovery surrounding a restored wetland using the normalized difference infrared index (NDII) and normalized difference vegetation index (NDVI). 
International Journal of Remote Sensing, 39(10), pp.3243-3274.

Xie, Y., Sha, Z. and Yu, M., 2008. Remote sensing imagery in vegetation mapping: a review. Journal of plant ecology, 1(1), pp.9-23.

Xue, J. and Su, B., 2017. Significant remote sensing vegetation indices: A review of developments and applications. Journal of Sensors, 2017.

Yu, H., Li, L., Zhu, W., Piao, D., Cui, G., Kim, M., Jeon, S.W. and Lee, W.K., 2019. Drought monitoring of the wetland in the Tumen River Basin between 1991 and 2016 using Landsat TM/ETM+. International Journal of Remote Sensing, 40(4), pp.1445-1459.

Zhao, M., Velicogna, I. and Kimball, J.S., 2017. A global gridded dataset of grace drought severity index for 2002-14: Comparison with pdsi and spei and a case study of the Australia millennium drought. Journal of Hydrometeorology, 18(8), pp.2117-2129.

\section{Figures}

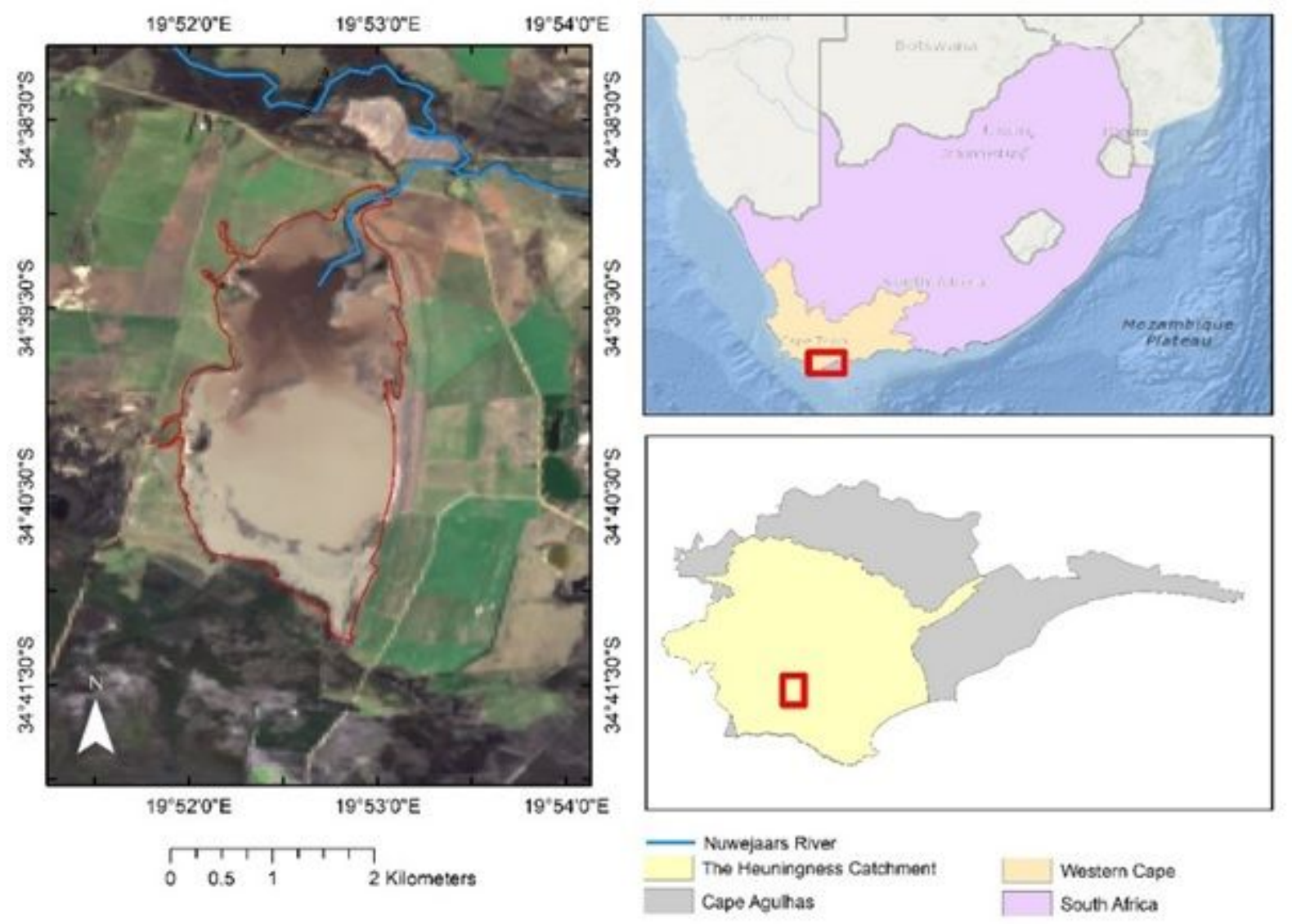

Figure 1

Location of the Soetendalsvlei in the Heuningnes Catchment, South Africa 


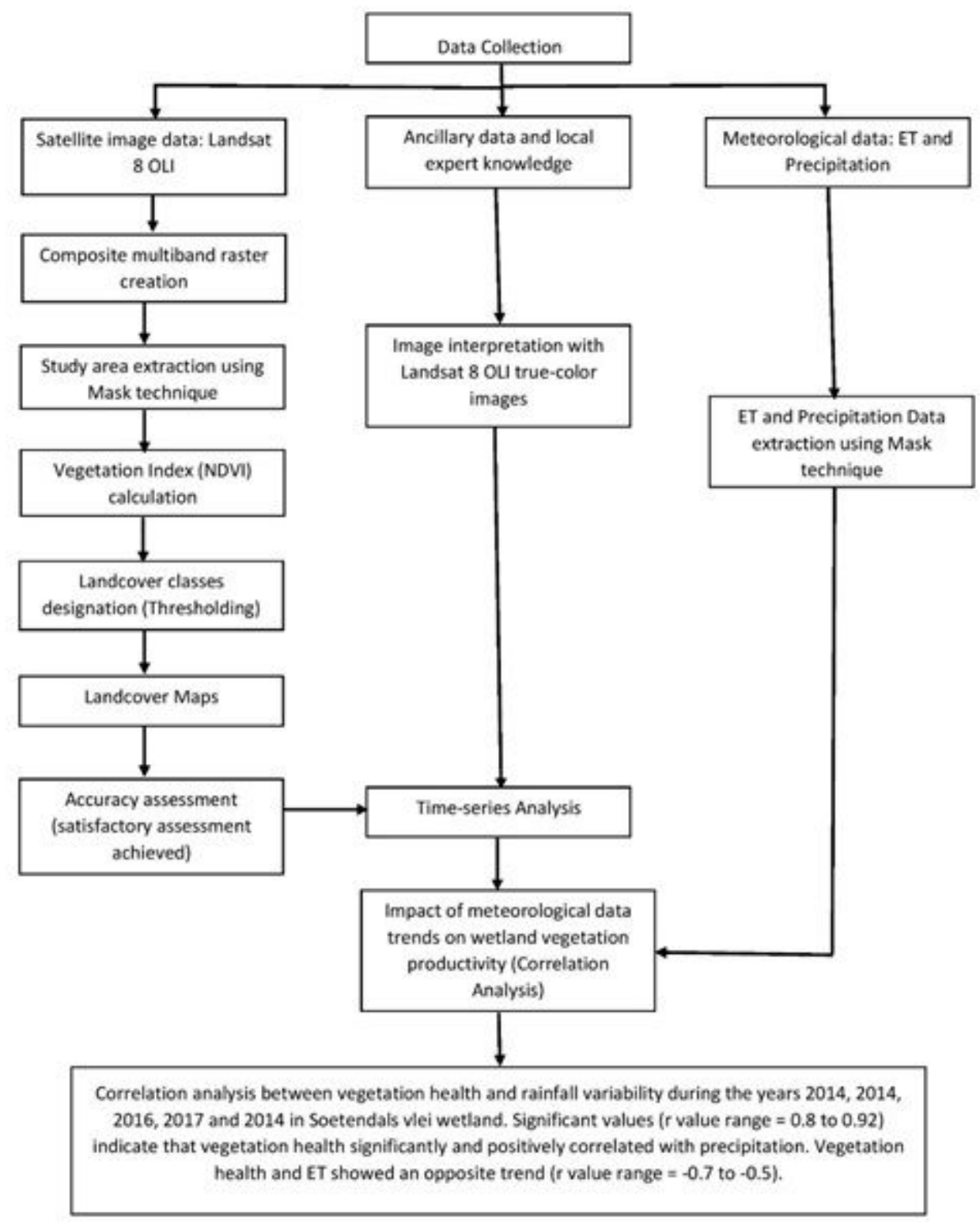

\section{Figure 2}

Methodological workflow used for wetland vegetation mapping and assessment of 2014-2018 drought impact 


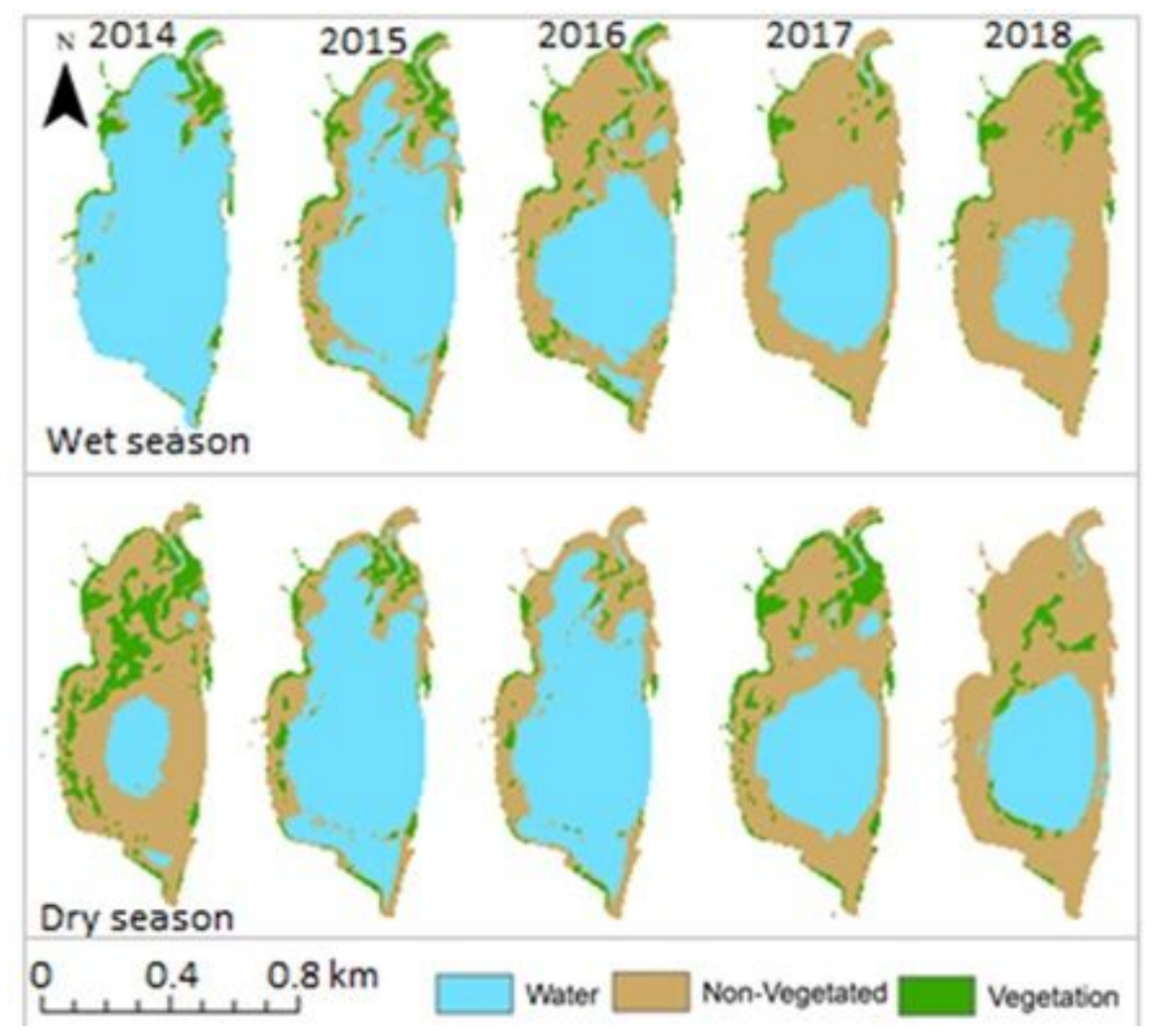

\section{Figure 3}

Remotely sensed derived wetland vegetation for the Sondentalsvlei in the Heuningnes catchment, South Africa

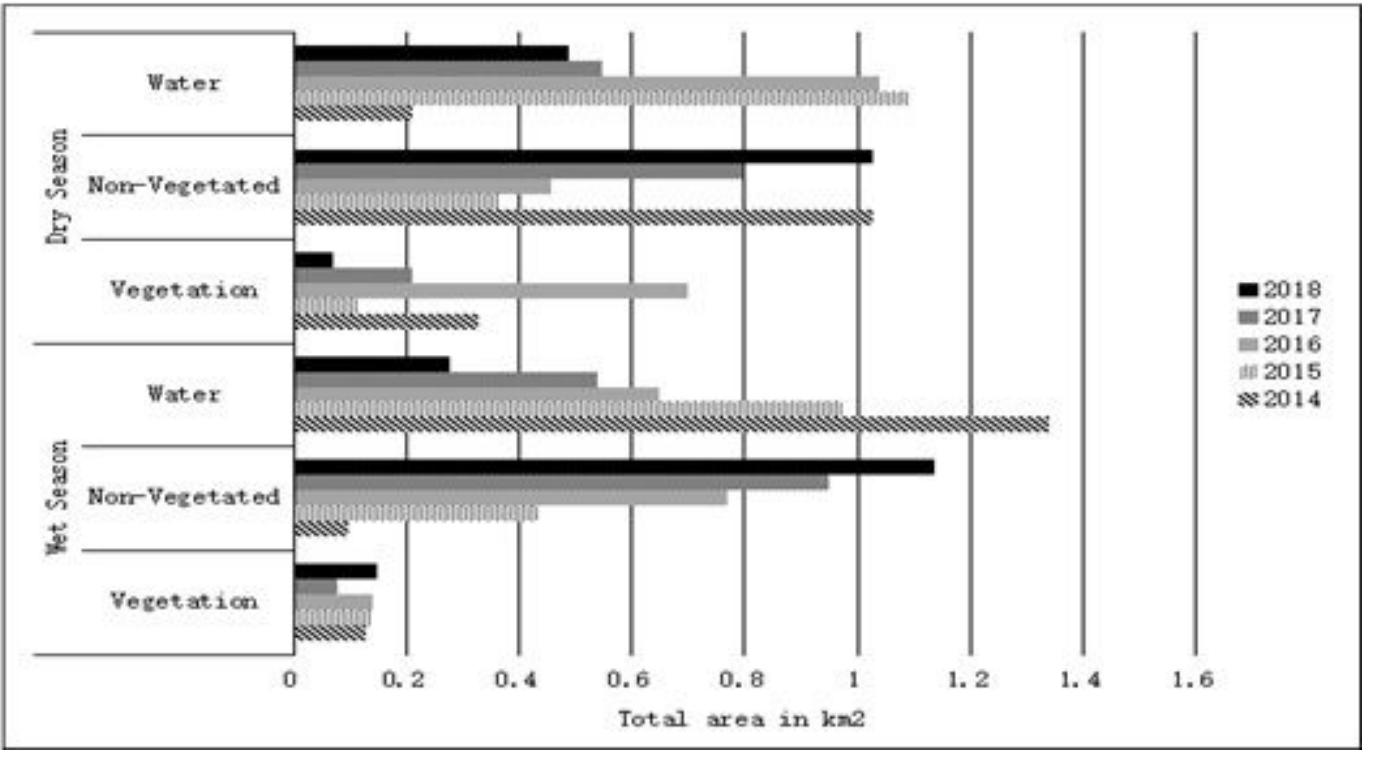

\section{Figure 4}

Detailed statistics on the areal extents and observed changes in wetland vegetation between the wet and dry season for the entire monitoring period 


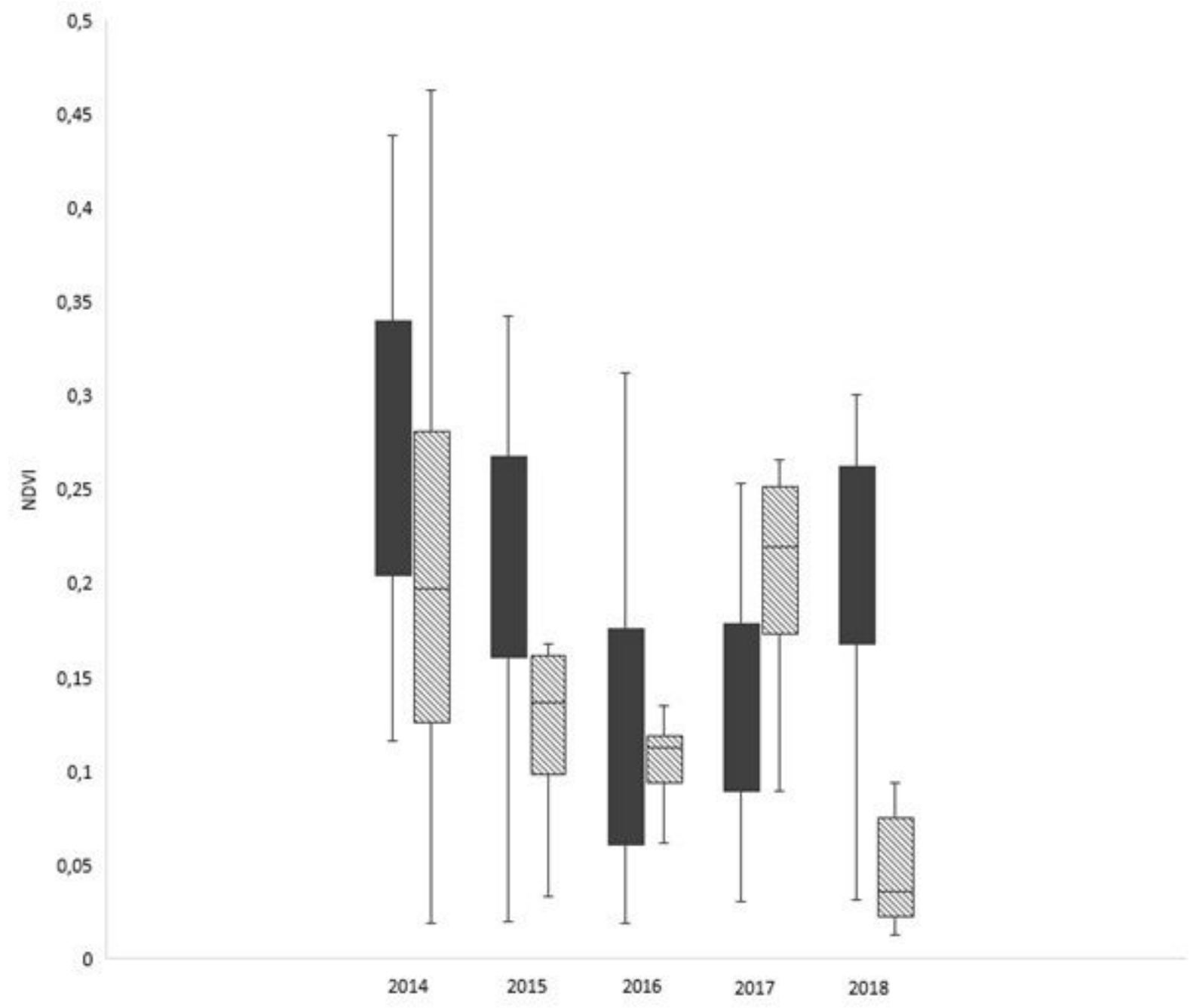

Figure 5

Seasonal and inter-annual variations and trends in wetland vegetation productivity 


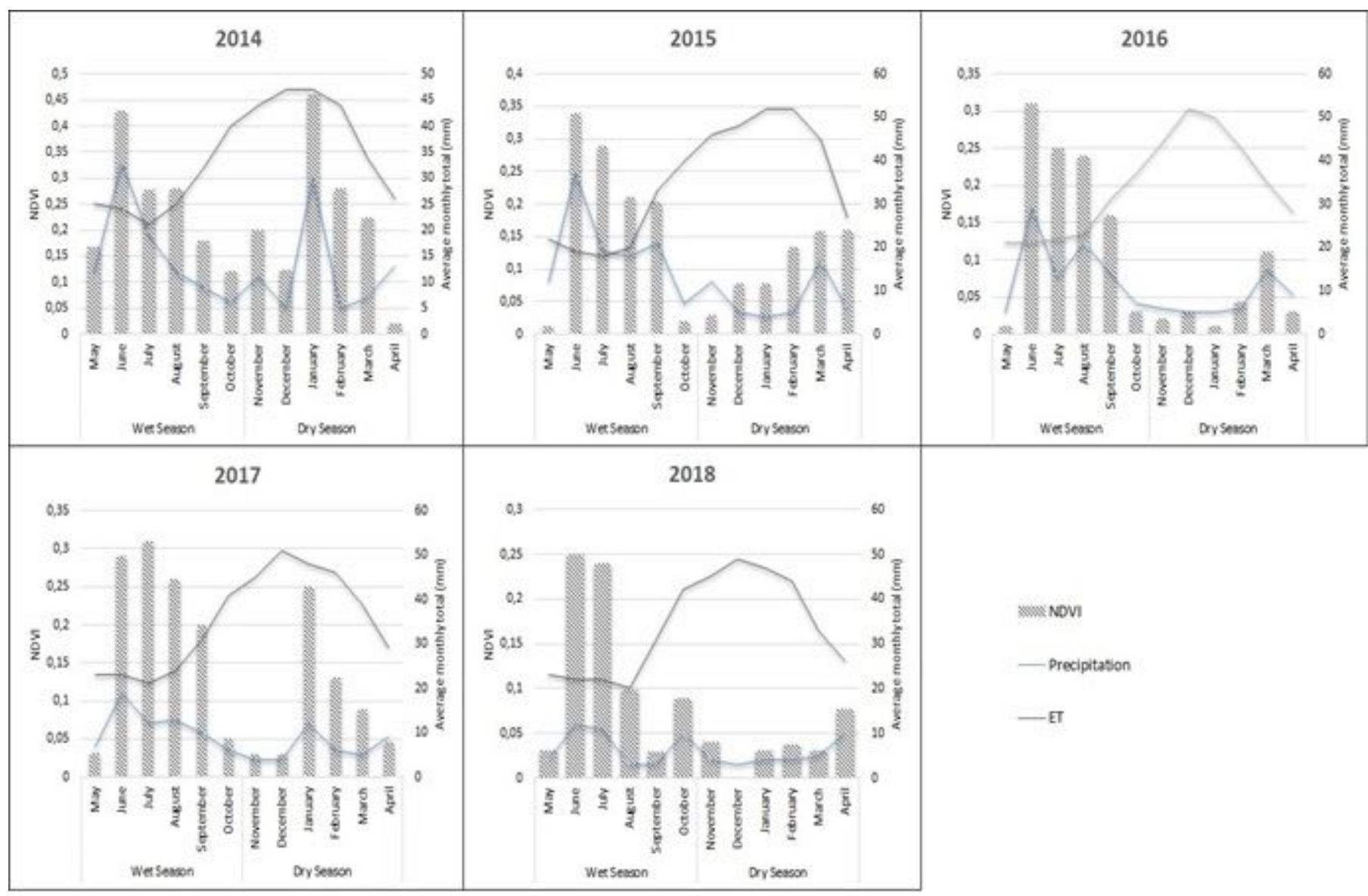

Figure 6

Monthly NDVI, precipitation and evapotranspiration relationships for the entire period under study 20142018 